\title{
DISSIPAÇÃO DOS INSETICIDAS BIFENTRINA, PERMETRINA E METAMIDOFÓS EM FOLHAS \\ DE SOJ A (Glycine max L.) EM AMBIENTE PROTEGIDO
}

RÔMULO PENNA SCORZA JÚNIOR*

RENÊ LUÍS DE OLIVEIRA RIGITANO**

\begin{abstract}
Este trabalho teve como objetivo estudar a dissipação dos inseticidas bifentrina, permetrina e metamidofós em folhas de soja em ambiente controlado. O experimento foi conduzido em casa de vegetação na Embrapa Agropecuária Oeste, em Dourados, MS, durante os meses de maio a julho de 2006. Utilizou-se delineamento experimental inteiramente ao acaso com parcelas subdivididas no tempo e quatro repetições. Os tratamentos corresponderam a aplicação dos inseticidas bifentrina, permetrina e metamidofós nas doses 0,11 g i.a. $L^{-1}, 0,36$ g i.a. $L^{-1}$ e 2,14 g i.a. $L^{-1}$, respectivamente. Aos 0, 2, 5, 10 e 17 dias da aplicação dos inseticidas, oito folhas de cada repetição foram coletadas e armazenadas a $-15^{\circ} \mathrm{C}$. Resíduos dos inseticidas nas folhas foram extraídos em acetona, purificados em cromatoplacas de sílica gel e quantificados em sistema de cromatografia gás-líquido (metamidofós) e em sistema de cromatografia a líquido de alta eficiência (permetrina e bifentrina). Para todos os inseticidas estudados, o decréscimo da concentração em função do tempo seguiu a cinética de primeira ordem. Os valores de coeficientes de dissipação com os respectivos errospadrão foram de $0,085 \pm 0,007 \mathrm{dia}^{-1}$ para 0 metamidofós, $0,015 \pm 0,004 \mathrm{dia}^{-1}$ para a permetrina e 0,045 $\pm 0,004$ dia $^{-1}$ para a bifentrina. Os valores de meia-vida de 8,1 dias para o metamidofós, 15,4 dias para a bifentrina e 45,5 dias para a permetrina indicaram maior persistência da permetrina nas condições estudadas.
\end{abstract}

PALAVRAS-CHAVE: BIFENTRINA; PERMETRINA; METAMIDOFÓS; PERSISTÊNCIA EM FOLHAS; MEIAVIDA.

* $\quad$ Ph.D. em Ciências Ambientais, Pesquisador da Embrapa Agropecuária Oeste, Dourados, MS (e-mail: romulo@cpao.embrapa.br).

** Ph.D. em Toxicologia de Inseticidas, Professor Titular, Universidade Federal de Lavras, Lavras, MG (rigitano@ufla.br). 


\section{INTRODUÇÃO}

A persistência de inseticidas nas folhas de plantas cultivadas tem efeito direto na eficiência do controle de pragas, no potencial de contaminação dos recursos naturais e também na determinação do intervalo de tempo exigido entre a aplicação do inseticida na lavoura e sua liberação para a entrada de pessoas. De maneira geral, a persistência dos inseticidas é definida como o tempo de sua permanência ativa em determinado substrato, sendo expressa em unidade de tempo (HIMEL, LOATS e BAILEY, 1990). Diversos processos afetam a persistência dos inseticidas após sua aplicação nas plantas como, por exemplo, fotodecomposição, degradação química e biológica, volatilização, absorção pela cutícula da folha e lavagem pela água da chuva. Diferenças na forma e permeabilidade da cutícula das folhas influenciam a quantidade do inseticida absorvido. Outro fator importante é a polaridade da molécula (LINDERS et al., 2000). Moléculas lipofílicas (apolares) podem penetrar mais facilmente na cutícula das folhas, tornando-se mais persistentes por estarem mais protegidas dos processos de dissipação (WILLIS e McDOWELL, 1987).

Vários estudos mostram que o declínio da concentração dos inseticidas nas folhas das plantas, após sua aplicação, segue a cinética de primeira ordem (WILLIS e McDOWELL, 1987). Com isso, tem-se utilizado o cálculo dos valores de meia-vida de dissipação para comparar a persistência de diferentes inseticidas. FRANCO, RIGITANO e GOUVEA (2001) observaram valores de meia-vida entre 3,8 e 4,8 dias para o metamidofós, após a sua aplicação em plantas de alface cultivadas em casa de vegetação (temperatura em torno de $25^{\circ} \mathrm{C}$ ), em Lavras (MG). PAPADOPOULOU-MOURKIDOU, KOTOPOULOU e STYLIANIDIS (1989) estudaram a persistência de bifentrina em folhas de pessegueiro após aplicação em condições de campo na Grécia. Observaram valores de meia-vida entre 9 e 23 dias, com temperatura média diária durante o período experimental de $23,4^{\circ} \mathrm{C}$ e precipitação acumulada de $92 \mathrm{~mm}$.

Os inseticidas piretróides constituem importantes alternativas de controle químico das pragas da soja, quando comparados aos inseticidas fosforados e carbamatos, que geralmente apresentam alta toxicidade aos seres humanos. A maioria dos inseticidas piretróides em uso tem se mostrado persistente no campo devido, principalmente, à boa estabilidade das moléculas e ao tipo de formulação utilizada (ELLIOT, 1980). Estudos demonstrando a persistência dos inseticidas piretróides nas condições tropicais brasileiras são escassos.

O presente trabalho teve como objetivo geral estudar a persistência de dois inseticidas piretróides (bifentrina e permetrina) e um fosforado (metamidofós) em folhas de soja sob condições controladas de temperatura e umidade. Os objetivos específicos foram: (i) determinar quais dos três inseticidas é o mais persistente em folhas de soja; (ii) determinar os valores de meia-vida de dissipação dos três inseticidas em folhas de soja e (iii) quantificar o declínio da concentração dos três inseticidas ao longo do tempo nas folhas de soja.

\section{MATERIAL E MÉTODOS}

\subsection{INSTALAÇÃO DO EXPERIMENTO}

O experimento foi conduzido em casa de vegetação da Embrapa Agropecuária Oeste, em Dourados, MS. Utilizou-se a cultivar de soja BRS 239, numa densidade de semeadura de 10 sementes/ vaso, sendo o experimento instalado no dia 15/05/2006. Em cada vaso foram colocados dois quilos de substrato (solo da camada de $0-30 \mathrm{~cm}$ proveniente de área de cultivo de soja). Após a germinação e emergência das plântulas efetuou-se o desbaste no dia 25/05/2006, deixando apenas três plântulas por vaso. Realizou-se irrigação diária dos vasos, fornecendo quantidade de água suficiente para manutenção das plantas. Dados de temperatura e umidade relativa do ar foram registrados no interior da casa de vegetação, a cada duas horas, no período de 17/05/2006 a 27/07/2006, utilizando-se 
termohigrógrafo Thies ${ }^{\circledR}$ modelo 1.0670.10.005. Para controle de oídio (Erysiphe diffusa) pulverizou-se no dia 05/06/2006, a mistura piraclostrobina + epoxiconazol na dose $500 \mathrm{~mL} \mathrm{ha}^{-1} \mathrm{em}$ todas as plantas. A casa de vegetação utilizada no estudo conta com cobertura de plástico e quatro ventiladores, acionados quando a temperatura interna atinge $25^{\circ} \mathrm{C}$.

Utilizou-se delineamento experimental inteiramente casualizado com parcelas subdivididas (ZIMMERMANN, 2004), sendo os tratamentos (inseticidas) alocados nas parcelas e as datas de amostragem (tempo) nas subparcelas. Foram utilizados 48 vasos (4 vasos/parcela), sendo 12 parcelas resultantes de 3 tratamentos (inseticidas) com 4 repetições.

\subsection{APLICAÇÃO DOS INSETICIDAS}

Os tratamentos corresponderam a uma aplicação dos inseticidas bifentrina, permetrina e metamidofós nas plantas de soja no dia 10/07/2006 às 08h30m. Para aplicação utilizou-se pulverizador de pressão constante $\left(\mathrm{CO}_{2}\right)$, equipado com bico Jacto $\mathrm{n}^{\circ} 14 \mathrm{com}$ caracol de um furo, pressão de $40 \mathrm{lbf} \mathrm{pol}^{-2}$ e volume de calda igual a $140 \mathrm{~L} \mathrm{ha}^{-1}$. As doses utilizadas foram $0,11 \mathrm{~g} \mathrm{i.a.} \mathrm{L}^{-1}$ de bifentrina, $0,36 \mathrm{~g}$ i.a. $\mathrm{L}^{-1}$ de permetrina e $2,14 \mathrm{~g}$ i.a. $\mathrm{L}^{-1}$ de metamidofós. Para a aplicação dos inseticidas, os vasos de cada parcela com as plantas de soja foram temporariamente transferidos para o exterior da casa de vegetação, sendo as plantas individualmente pulverizadas até o ponto de escorrimento.

\subsection{COLETADAS AMOSTRAS}

Aos $0,2,5,10$ e 17 dias da aplicação dos inseticidas, oito folhas de soja foram coletadas em cada repetição. As folhas foram retiradas nos terços inferior, médio e superior das plantas, procurando-se aquelas uniformes quanto ao tamanho e sem lesões. As amostras foram acondicionadas em papel alumínio, colocadas em sacos plásticos com a devida identificação e armazenadas em freezer a $-15^{\circ} \mathrm{C}$ até o momento do envio para o Laboratório de Toxicologia de Inseticidas da Universidade Federal de Lavras (UFLA), Lavras (MG). O tempo decorrido entre a coleta das folhas, identificação e armazenamento no freezer foi de 60 minutos. Para o envio, as amostras foram acondicionadas em recipiente térmico contendo gelo seco. A extração, purificação e quantificação dos inseticidas nas folhas de soja ocorreram no Laboratório de Toxicologia de Inseticidas da UFLA.

\subsection{METODOLOGIA ANALÍTICA}

Os métodos analíticos utilizados para as determinações dos teores dos inseticidas nas folhas foram baseados nas metodologias descritas por RIDLER (1992), KAUSHIK e HANDA (1997), METWALLY, OSMAN e AL-RUSHAID (1997) para bifentrina e permetrina, e BLA $\beta$ e PHILIPOWSKI (1995) e FRANCO et al. (2001) para o metamidofós. Os compostos foram extraídos em acetona, purificados em cromatoplacas de sílica gel e quantificados em sistema de cromatografia gás-líquido no caso do metamidofós, e em sistema de cromatografia a líquido de alta eficiência para os piretróides.

\subsection{EXTRAÇÃO E PURIFICAÇÃO DOS COMPOSTOS}

Os compostos foram extraídos das folhas com auxílio de gral e pistilo, usando-se acetona como solvente extrator. Filtrou-se o extrato em lã de vidro e ajustou-se o volume final para $100 \mathrm{~mL}$. Uma alíquota de $5 \mathrm{~mL}$ do extrato foi transferida para balão de fundo redondo $(50 \mathrm{cc})$ e submetida à evaporação da acetona (e da água proveniente da amostra) em rotaevaporador com banho a $50^{\circ} \mathrm{C}$. Em seguida, usando-se pipeta de tipo Pasteur e procedendo-se três lavagens sucessivas com $0,25 \mathrm{~mL}$ de acetona, os resíduos foram transferidos ao longo da linha a $3 \mathrm{~cm}$ da base para placa de cromatografia 
de camada delgada de $20 \times 10 \mathrm{~cm}$, contendo sílica gel $\mathrm{GF}_{254}(0,5 \mathrm{~mm})$. Nas laterais da placa foram colocados pequenos volumes das soluções de bifentrina ou permetrina, em acetona, para visualização dos compostos na placa, sob luz ultra-violeta $(254 \mathrm{~nm})$. Para metamidofós utilizou-se o inseticidanematicida oxamil como marcador, conforme FRANCO, RIGITANO e GOUVEA (2001), uma vez que esses compostos apresentam fatores de retenção muito próximos nas placas e, diferentemente do oxamil, o metamidofós não é visível sob luz ultra-violeta. Como fases móveis foram utilizadas as misturas hexano e acetona (10:1) para os piretróides, e éter etílico e acetona (10:2) para o metamidofós. Os fatores de retenção dos compostos nas placas foram: 0,44 para o marcador oxamil e 0,64 para a bifentrina. No caso da permetrina observou-se a separação dos isômeros cis e trans na placa, com fatores de retenção muito próximos $(0,56$ e 0,60$)$.

Após resolução da cromatografia, a sílica correspondente à faixa de $3 \mathrm{~cm}$ delimitada com base na visualização dos padrões ( $1,5 \mathrm{~cm}$ acima e abaixo do centro da mancha do padrão) foi raspada $\mathrm{e}$ transferida para funil de vidro contendo lã de vidro e suspensa em balão de fundo redondo (50 cc). Em seguida, os resíduos foram removidos da sílica por meio de três lavagens sucessivas com $5 \mathrm{~mL}$ de acetona. Após eliminação da acetona em rotavapor, os resíduos foram diluídos em $2 \mathrm{~mL}$ de acetona no caso do metamidofós e em $2 \mathrm{~mL}$ de acetonitrila para os piretróides, sendo as soluções desses últimos passadas em filtro PTFE $(0,45 \mu \mathrm{m})$ com auxílio de seringa. Os frascos contendo essas soluções foram armazenados em freezer a $-15^{\circ} \mathrm{C}$ até o momento da quantificação dos compostos.

\subsection{QUANTIFICAÇÃO DOS COMPOSTOS}

Efetuou-se a quantificação do metamidofós nos extratos purificados em sistema de cromatografia gás-líquido (HP 6890), com detector termiônico (NPD). Utilizou-se coluna HP-5 ( $5 \%$ de metil-fenil-siloxano), com $0,25 \mu \mathrm{m}$ de espessura de filme, $30 \mathrm{~m}$ de comprimento e $0,32 \mathrm{~mm}$ de diâmetro interno. As condições de operação foram: temperatura do forno $-100^{\circ} \mathrm{C}$ (1 min) ' $\rightarrow 30^{\circ} \mathrm{C} \mathrm{min}^{-1}{ }^{\prime} \rightarrow 160^{\circ} \mathrm{C}(1 \mathrm{~min})^{\prime} \rightarrow 30^{\circ} \mathrm{C} \mathrm{min}^{-1}{ }^{\prime} \rightarrow 220^{\circ} \mathrm{C}$ (1 min); temperatura do injetor $220^{\circ} \mathrm{C}$; temperatura do detector $-300^{\circ} \mathrm{C}$; fluxo do gás de arraste $\left(\mathrm{N}_{2}\right)-2,3 \mathrm{~mL} \mathrm{~min}{ }^{-1}$ ("make up": $30 \mathrm{~mL} \mathrm{~min}$ ); fluxo de ar sintético - $60 \mathrm{~mL} \mathrm{~min}^{-1}$; fluxo de $\mathrm{H}_{2}-3,0 \mathrm{~mL} \mathrm{~min}{ }^{-1}$; modo de injeção splitless; tempo de purga - 2 minutos; volume de injeção - $1 \mu \mathrm{L}$. Nessas condições, o tempo de retenção do composto foi de 3,8 minutos.

As determinações de bifentrina e permetrina ocorreram em sistema de cromatografia a líquido de alta eficiência, modelo Agilent 1100, operando com detector de ultra-violeta $(230 \mathrm{~nm})$. Utilizou-se coluna LiChroCART ( $25 \mathrm{~cm}$ de comprimento e $3 \mathrm{~mm}$ de diâmetro interno), preenchida com LiChrospher RP-18 (5 $\mu \mathrm{m})$. Como fase móvel usou-se mistura de acetonitrila e água Milli-Q, na proporção 95:5, com fluxo de $0,3 \mathrm{~mL} \mathrm{~min}{ }^{-1}$. Fixou-se o volume de injeção em $20 \mu \mathrm{L}$ e o tempo de retenção da bifentrina foi de 10,5 minutos, com um único pico observado. No caso da permetrina observou-se a separação de seus isômeros cis e trans, com tempos de retenção de 9,2 e 9,9 min, sendo esses isômeros conjuntamente quantificados.

Para a quantificação dos compostos utilizaram-se padrões analíticos de bifentrina e permetrina, fornecidos pela FMC Química do Brasil Ltda., sendo o de metamidofós obtido junto à Bayer CropScience Ltda. As purezas dos padrões analíticos utilizados foram de $97 \%$ para a bifentrina, $94 \%$ para a permetrina e 99\% para o metamidofós. A eficiência dos métodos analíticos foi determinada analisando-se amostras de folhas fortificadas com os compostos nas concentrações de 1, 10 e $100 \mu \mathrm{g} \mathrm{g}^{-1}$ de folhas. Foram constatadas porcentagens de recuperação acima de $85 \%$ para os três compostos, sendo os resultados obtidos nas análises das amostras do experimento corrigidos de acordo com a porcentagem de recuperação verificada para cada composto.

\subsection{ANÁLISE DOS DADOS}

Os dados referentes às concentrações dos inseticidas nas diferentes datas de amostragem 
foram submetidos à análise de variância, utilizando-se o programa ASSISTAT (SILVA e AZEVEDO, 2002). Os dados do logaritmo neperiano da concentração remanescente dos diferentes inseticidas nas folhas de soja ao longo do tempo foram ajustados a uma equação linear, visando verificar se a dissipação segue cinética de primeira ordem (equação 1):

$$
\ln (C)=\ln \left(C_{0}\right)-k \cdot t
$$

Em que:

$\ln (C)=$ logaritmo neperiano da concentração remanescente nas folhas $\left(\mu \mathrm{g} \mathrm{g}^{-1}\right)$;

$\ln (\mathrm{CO})=$ logaritmo da concentração inicial $\left(\mu \mathrm{g} \mathrm{g}^{-1}\right)$;

$k=$ coeficiente de dissipação $\left(\right.$ dia $\left.^{-1}\right) ; \mathrm{e}$

$t=$ tempo (dias).

Calculou-se o valor de meia-vida (DT50), em dias, pela equação 2:

$$
D T 50=\frac{0,693}{k}
$$

\section{RESULTADOS E DISCUSSÃO}

Os resultados referentes às concentrações remanescentes dos três inseticidas encontrados nas folhas de soja após 0, 2, 5, 10 e 17 dias da sua aplicação são apresentados na Tabela 1. A concentração média remanescente diminuiu ao longo do tempo para todos os inseticidas, indicando a ocorrência do processo de dissipação. Observou-se ainda pequena variabilidade das concentrações remanescentes dos inseticidas nas diferentes repetições e datas de amostragem, confirmada pelos baixos valores do desvio-padrão em cada data de amostragem (Tabela 1).

\section{TABELA 1 - CONCENTRAÇÕES REMANESCENTES DE PERMETRINA, BIFENTRINA E METAMIDOFÓS EM FOLHAS DE SOJA AOS 0, 2, 5, 10 E 17 DIAS APÓS SUA APLICAÇÃO

\begin{tabular}{|c|c|c|c|c|c|c|}
\hline \multirow{3}{*}{ Inseticida } & \multirow{3}{*}{$\mathrm{DAA}^{\mathrm{a}}$} & \multicolumn{5}{|c|}{ Concentrações ( $\mu \mathrm{g} \mathrm{g}^{-1}$ de folha) } \\
\hline & & \multicolumn{4}{|c|}{ Repetições } & \multirow{2}{*}{ Média $\pm D P^{b}$} \\
\hline & & 1 & 2 & 3 & 4 & \\
\hline \multirow{5}{*}{ Permetrina } & 0 & 189 & 205 & 147 & 153 & $174 \pm 28$ \\
\hline & 2 & 143 & 189 & 150 & 161 & $161 \pm 20$ \\
\hline & 5 & 183 & 134 & 163 & 141 & $155 \pm 22$ \\
\hline & 10 & 147 & 133 & 150 & 129 & $140 \pm 10$ \\
\hline & 17 & 142 & 124 & 126 & 135 & $132 \pm 8$ \\
\hline \multirow{5}{*}{ Bifentrina } & 0 & 54 & 41 & 46 & 47 & $47 \pm 5$ \\
\hline & 2 & 45 & 40 & 40 & 47 & $43 \pm 4$ \\
\hline & 5 & 40 & 34 & 32 & 42 & $37 \pm 5$ \\
\hline & 10 & 29 & 27 & 34 & 25 & $29 \pm 4$ \\
\hline & 17 & 26 & 18 & 21 & 24 & $22 \pm 4$ \\
\hline \multirow{5}{*}{ Metamidofós } & 0 & 1072 & 759 & 945 & 890 & $917 \pm 130$ \\
\hline & 2 & 775 & 754 & 727 & 801 & $764 \pm 31$ \\
\hline & 5 & 652 & 694 & 615 & 714 & $669 \pm 44$ \\
\hline & 10 & 332 & 267 & 297 & 315 & $303 \pm 28$ \\
\hline & 17 & 306 & 278 & 201 & 179 & $241 \pm 61$ \\
\hline
\end{tabular} NAS PLANTAS - DOURADOS, MS/2007}

${ }^{a}$ DAA = Dias após aplicação.

${ }^{\mathrm{b}} \mathrm{DP}=$ Desvio-padrão. 
Com o objetivo de verificar a coerência das proporções entre a quantidade aplicada e recuperada, logo após a pulverização dos diferentes inseticidas, calculou-se essas relações utilizando os valores das seguintes doses aplicadas: 0,357 g i.a. $\mathrm{L}^{-1}$ para a permetrina, 0,107 g i.a. $\mathrm{L}^{-1}$ para a bifentrina e $2,142 \mathrm{~g}$ i.a. $\mathrm{L}^{-1}$ para o metamidofós. Assim, as proporções entre as doses aplicadas foram de: permetrina/bifentrina $=3,70$; metamidofós $/$ permetrina $=5,30$ e metamidofós $/$ bifentrina $=19,5$. Já as proporções entre as quantidades recuperadas logo após a aplicação (0 dia) foram de: permetrina/ bifentrina $=3,34$; metamidofós/permetrina $=6,00$ e metamidofós $/$ bifentrina $=20,02$. Com isso, constatase grande coerência das proporções entre as quantidades aplicadas e recuperadas para todos os inseticidas estudados.

A Tabela 2 apresenta o resumo da análise de variância, cuja interação entre inseticidas e tempo após aplicação foi significativa $(P<0,01)$. Dessa forma, procedeu-se a análise de regressão entre 0 logaritmo neperiano da concentração remanescente do inseticida na folha em função do tempo após aplicação (conforme Equação 1), procurando ajuste à cinética de primeira ordem para descrever a dissipação (Figura 1). Para todos os inseticidas estudados, as relações entre o logaritmo neperiano da concentração remanescente e o tempo após a aplicação foram significativas $(P<0,01)$, com valores de coeficiente de determinação $\left(R^{2}\right)$ igual a 0,89 para o metamidofós, 0,85 para a bifentrina e 0,41 para a permetrina. Isso mostra boa qualidade do ajuste à equação linear para os inseticidas, com exceção da permetrina.

\section{TABELA 2 - RESUMO DA ANÁLISE DE VARIÂNCIA PARA OS DADOS DE CONCENTRAÇÃO REMANESCENTE DOS INSETICIDAS PERMETRINA, BIFENTRINA E METAMIDOFÓS EM FOLHAS DE SOJA AOS 0, 2, 5, 10 E 17 DIAS APÓS SUA APLICAÇÃO NAS PLANTAS - DOURADOS, MS/2007}

\begin{tabular}{ccc}
\hline Causas de Variação & Graus de Liberdade & Quadrado Médio \\
\hline Inseticidas (Parcela) & 2 & $1635528,22^{* *}$ \\
Erro (Parcela) & 9 & 2146,33 \\
\hline Parcelas & 11 & - \\
\hline Tempo (Sub-Parcela) & 4 & $137329,18^{\text {** }}$ \\
Interação Inseticidas x Tempo & 8 & $105514,13^{* *}$ \\
Erro (Sub-Parcela) & 36 & 1645,05 \\
\hline Total & 59 & - \\
\hline
\end{tabular}

** Significativo ao nível de 1\%; Coeficiente de variação da parcela = 18,1\%; Coeficiente de variação da sub-parcela $=15,9 \%$.

O baixo valor de $\mathrm{R}^{2}$ para a permetrina decorre da sua lenta dissipação, gerando valor do coeficiente de dissipação próximo à zero para o intervalo de tempo estudado (17 dias). Isso mostra a necessidade de aumentar o intervalo de tempo para o estudo da dissipação da permetrina, já que 17 dias não foram suficientes para gerar estimativa confiável do valor de $k$ (coeficiente de dissipação) e, conseqüentemente, da DT50 (meia-vida). Os valores estimados de $k$ com base na Figura 2 foram iguais a $0,085 \pm 0,007^{1} \mathrm{dia}^{-1}$ para o metamidofós, $0,015 \pm 0,004 \mathrm{dia}^{-1}$ para a permetrina e $0,045 \pm 0,004$ dia $^{-1}$ para a bifentrina. Em termos estatísticos pode-se dizer que ocorreu dissipação diária de $8,5 \%$ da dose aplicada de metamidofós nas folhas de soja, de 1,5\% para permetrina e de $4,5 \%$ para a bifentrina durante o período do estudo (17 dias). Com base nos valores de $k$ e na Equação 2 obtiveram-se valores de DT50 iguais a 8,1 dias para o metamidofós, 45,5 dias para a permetrina e 15,4 dias para a bifentrina. Assim, para que se tenha dissipação de $50 \%$ da dose aplicada foram necessários 8,1 dias para o metamidofós, 45,5 dias para a permetrina e 15,4 dias para a bifentrina. Importante ressaltar que esses valores de DT50 foram fortemente influenciados pelas condições de temperatura e umidade. 


\section{FIGURA 1-RELAÇÃO ENTRE AS CONCENTRAÇÕES REMANESCENTES DOS INSETICIDAS METAMIDOFÓS (A), BIFENTRINA (B) E PERMETRINA (C) NAS FOLHAS DE SOJA E O TEMPO APÓS SUA APLICAÇÃO - DT5O = MEIA-VIDA}
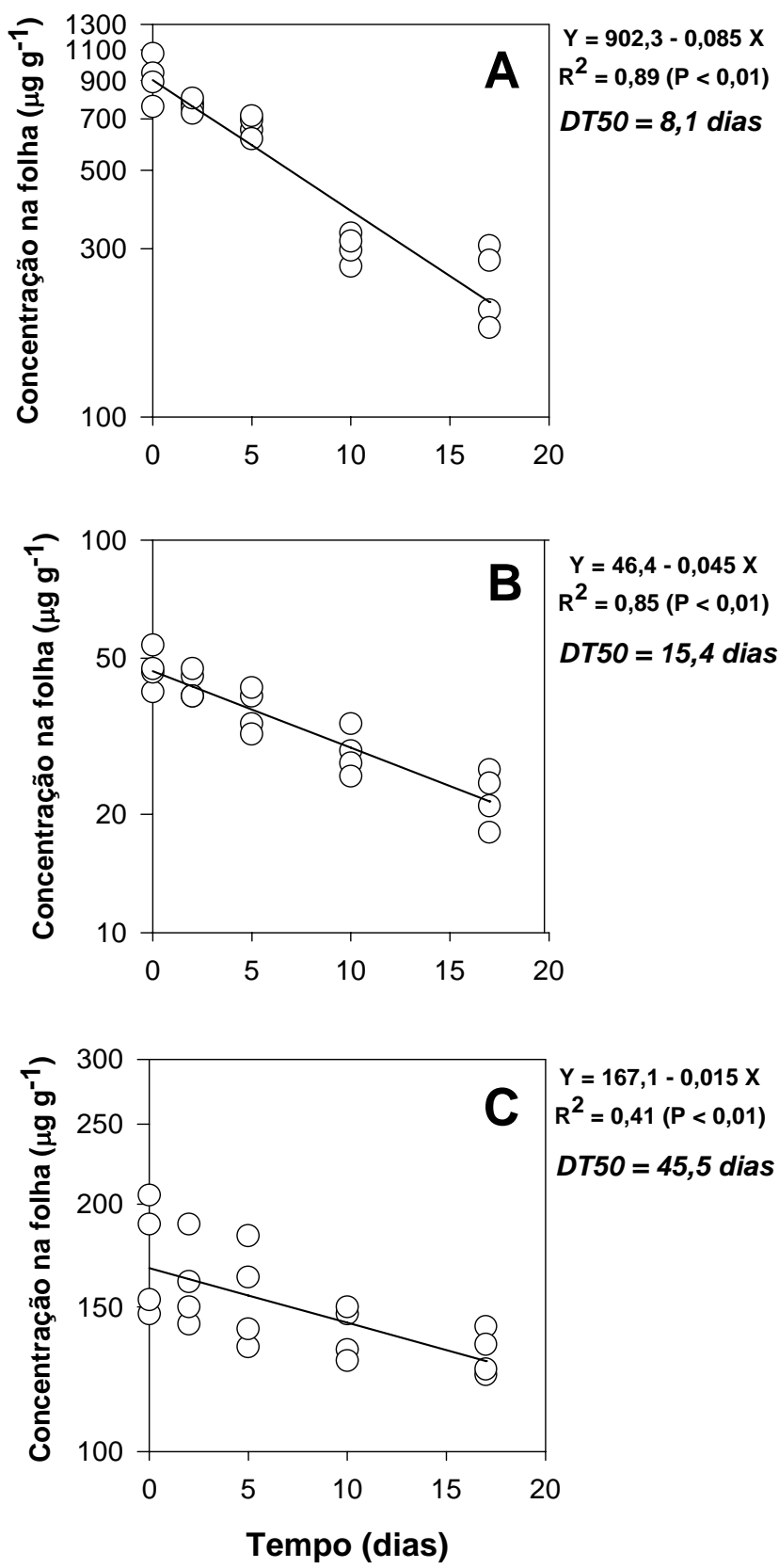

Os valores médios de temperatura e umidade relativa no interior da casa de vegetação (Figura 2), após a aplicação dos inseticidas foram de $20,2 \pm 2,8^{\circ} \mathrm{C}$ e $76,5 \pm 8,1 \%$, respectivamente. Assim, o inseticida que se mostrou mais persistente nas folhas de soja para as condições estudadas de temperatura e umidade foi a permetrina (seguida pela bifentrina e pelo metamidofós).

O valor de DT50 para metamidofós (8,1 dias) encontrado nesse estudo foi superior ao observado por FRANCO, RIGITANO e GOUVEA (2001), entre 3,8 e 4,8 dias. Esses autores aplicaram metamidofós em plantas de alface na condição de temperatura média de $25^{\circ} \mathrm{C}$. Tal diferença de temperatura, $5^{\circ} \mathrm{C}$ superior a do presente estudo $\left(20,2^{\circ} \mathrm{C}\right)$, justifica a dissipação mais rápida e, portanto, valores menores de DT50. O valor de DT50 (15,4 dias) para bifentrina observado nesse estudo é intermediário aos encontrados por PAPADOPOULOU-MOURKIDOU, KOTOPOULOU e STYLIANIDIS (1989), que foram de 9 a 23 dias. Esses autores estudaram a dissipação de bifentrina em folhas de pessegueiro em 
condições de campo com temperatura média durante o período experimental de $23,4^{\circ} \mathrm{C}$. TEWARY et al. (2005) estudaram a dissipação de bifentrina em folhas da cultura de chá na Índia, em condições de campo, e observaram valores e meia-vida entre 0,52 e 1,32 dias. Com relação à permetrina, relatos na literatura confirmam sua alta persistência no ambiente. SUNDARAM, HELSON e DAYNE (1992) relatam valores de meia-vida de permetrina em folhas de diferentes espécies florestais de até 363 dias.

\section{FIGURA 2 - DADOS DIÁRIOS DE TEMPERATURA E UMIDADE RELATIVA OBSERVADOS NO INTERIOR DA CASA DE VEGETAÇÃO PARA O PERÍODO DE 17/05/2006 A 27/07/2006 DOURADOS, MS/2007}
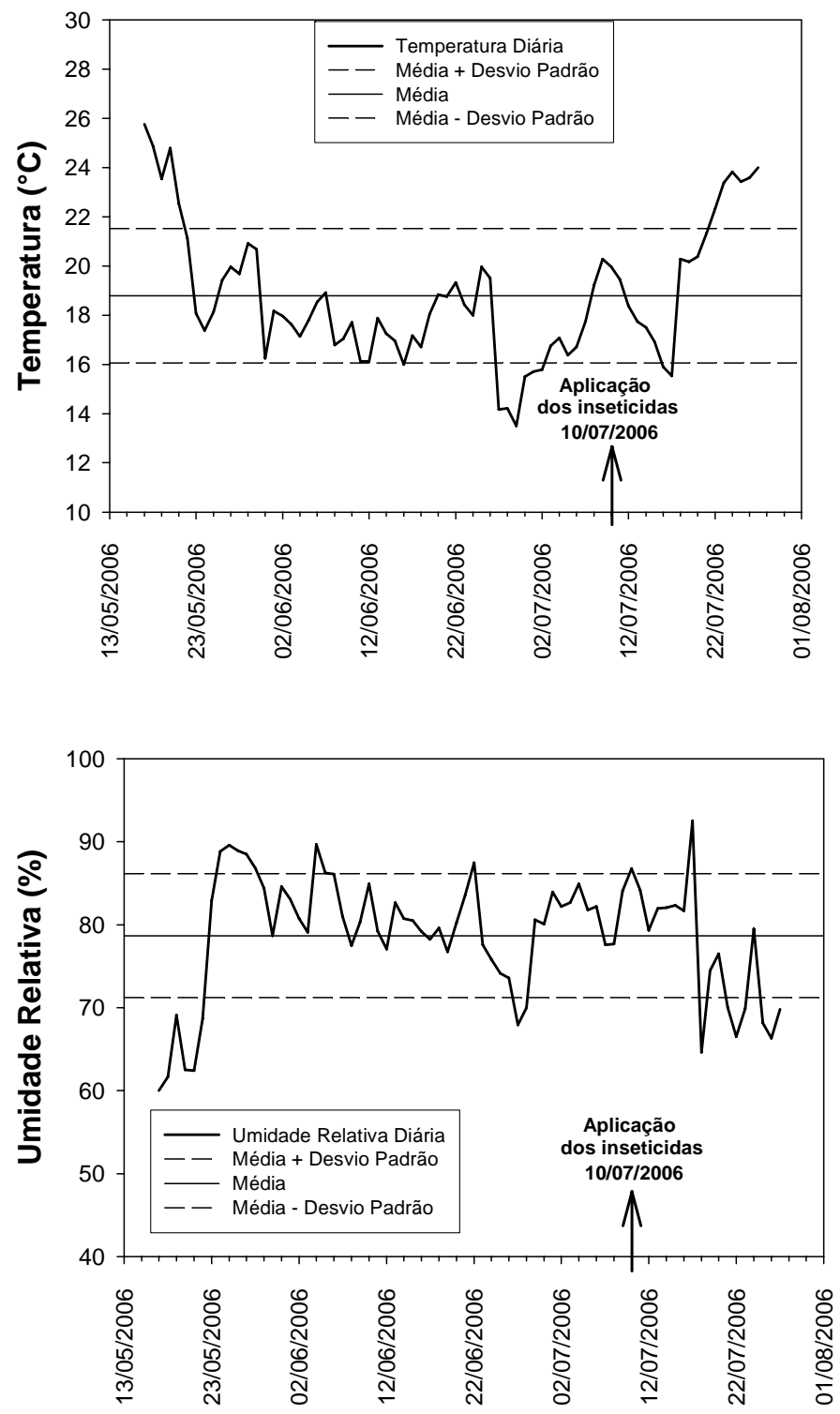

\section{CONCLUSÃO}

Dentre os três inseticidas estudados, a permetrina mostrou-se mais persistente (DT50 $=45,5$ dias) nas folhas de soja para as condições estudadas de temperatura e umidade, seguida pela bifentrina ( $D T 50=15,4$ dias) e metamidofós ( $D T 50=8,1$ dias). 


\section{ABSTRACT}

\section{DISSIPATION OF THE INSECTICIDES BIFENTHRIN, PERMETHRIN, AND METHAMIDOPHOS ON SOYBEAN}

LEAVES (Glycine max L.) UNDER PROTECTED ENVIRONMENT

This work had as objective to study the dissipation of the insecticides Bifenthrin, Permethrin, and, Methamidophos on soybean leaves under controlled environment. The experiment was carried out in a greenhouse at Embrapa Agropecuária Oeste in Dourados, Mato Grosso do Sul State (BRAZIL), between May and July 2006. The experimental design was a completely randomized with split-plot in time and four replications. Treatments were one application of the insecticides Bifenthrin, Permethrin, and Methamidophos at rates of $0.11 \mathrm{~g}$ a.i. $\mathrm{L}^{-1}, 0.36 \mathrm{~g}$ a.i. $\mathrm{L}^{-1}$, and $2.14 \mathrm{~g}$ a.i. $\mathrm{L}^{-1}$, respectively. At $0,2,5,10$, and 17 days after insecticide application, eight leaves were collected from each replication and stored at $-15^{\circ} \mathrm{C}$. Insecticide residues on leaves were extracted in acetone, purified on silica gel T.L.C. plates and determined by gasliquid chromatography for methamidophos and by high-performance liquid chromatography for Permethrin and Bifenthrin. For all insecticides, the decline of concentration as a function of time did fit first-order kinetics and resulted in dissipation coefficient values and their standard errors of $0.085 \pm 0.007$ day-1 for Methamidophos, $0.015 \pm 0.004$ day $^{-1}$ for Permethrin, and $0.045 \pm 0.004$ day $^{-1}$ for Bifenthrin. Half-life values were 8.1 days for methamidophos, 15.4 days for bifenthrin, and 45.4 days for permethrin, showing that permethrin was the most persistent insecticide under the studied conditions.

KEY-WORDS: BIFENTHRIN; PERMETHRIN; METHAMIDOPHOS; FOLIAGE PERSISTENCE; HALF-LIFE.

\section{REFERÊNCIAS}

1 BLA $\beta$, W.; PHILIPOWSKI, C. Gas-chromatographic method for the determination of methamidophos residues in material of plant origin, including processed products. Pflanzenschutz Nachrichten Bayer, Leverkusen, v. 48, n. 2, p. 353377, 1995.

2 ELLIOT, M. Established pyrethroids. Pesticide Science, Sussex, v. 11, p. 119-128, 1980.

3 FRANCO, A.A.; RIGITANO, R. L. O.; GOUVEA, A. V. Dissipação do inseticida metamidofós em plantas de alface (Lactuca sativa L.). Ciência e Agrotecnologia, Lavras, v. 25, n. 6, p. 1307-1313, 2001.

4 HIMEL, C. M.; LOATS, H.; BAILEY, G.W. Pesticide sources to the soil and principles of spray physics. In: CHENG, H.H. (Ed.). Pesticides in the soil environment: process, impacts, and modeling. Madison: SSSA, 1990. p. 7-50.

5 KAUSHIK, N.; HANDA, S.N. New clean-up method for gas chromatographic analysis of pyrethroids residues. Chromatographia, Braunschweig, v. 46, n. 3/4, p. 209-212, 1997.

6 LINDERS, J.; MENSINK, H.; STEPHENSON, G.; WAUCHOPE, D.; RACKE, K. Foliar interception and retention values after pesticide application. A proposal for standardized values for environmental risk assessment. Pure and Applied Chemistry, London, v. 72, n. 11, p. 2199-2218, 2000.

7 METWALLY, M. E. S.; OSMAN, M. S.; AL-RUSHAID, R. A high-performance liquid chromatographic method for the determination of cypermethrin in vegetables and its application to kinetic studies after greenhouse treatment. Journal of Agricultural and Food Chemistry, Washington, v. 59, n. 2, p. 283-290, 1997.

8 PAPADOPOULOU-MOURKIDOU, E.; KOTOPOULOU, A.; STYLIANIDIS, D. Field dissipation of the pyrethroid insecticide/ acaricide biphenthrin on the foliage of peach trees, in the peel and pulp of peaches, and in tomatoes. Annals of Applied Biology, Cambridge, v. 115, p. 405-416, 1989.

9 RIDLER, J.E. Residue analytical method of the determination of bifenthrin and 4'- hydroxyl bifenthrin in/ on corn matrices. Princeton: FMC Corporation - Agricultural Chemical Group, 1992. 48 p.

10 SILVA, F.A.S.; AZEVEDO, C.A.V. Versão do programa computacional ASSISTAT para o sistema operacional Windows. Revista Brasileira de Produtos Agroindustriais, Campina Grande, v. 4, n. 1, p. 71-78, 2002.

11 SUNDARAM, K.M.S.; HELSON, B.V.; PAYNE, N.J. Distribution and persistence of aerially sprayed permethrin in some terrestrial components of a boreal plantation forest. Journal of Agricultural and Food Chemistry, Washington, v.40, p.2523-2529, 1992.

12 TEWARY, D.K.; KUMAR, V.; RAVINDRANATH, S.D.; SHANKER, A. Dissipation behavior of bifenthrin residues in tea and its brew. Food Control, Amsterdam, v.16, p. 231-237, 2005.

13 WILLIS, G.H.; McDOWELL, L.L. Pesticide persistence on foliage. Reviews of Environmental Contamination and Toxicology, New York, v. 100, p. 23-73, 1987.

14 ZIMMERMANN, F.J.P. Estatística aplicada à pesquisa agrícola. Santo Antônio de Goiás: Embrapa Arroz e Feijão, 2004. $400 \mathrm{p}$. 


\section{AGRADECIMENTOS}

À FMC Química do Brasil Ltda. pelo auxílio financeiro e fornecimento dos padrões analíticos da permetrina e bifentrina. 